\title{
Bone Mineral Density and Trabecular Bone Score in Ukrainian Men with Obesity
}

\author{
Vladyslav Povoroznyuk, Anna Musiienko, Nataliia Dzerovych, Roksolana Povoroznyuk
}

\begin{abstract}
Osteoporosis and obesity are widespread diseases in people over 50 years associated with changes in structure and body composition. Higher body mass index (BMI) values are associated with greater bone mineral density (BMD). However, trabecular bone score (TBS) indirectly explores bone quality, independently of BMD. The aim of our study was to evaluate the relationship between the BMD and TBS parameters in Ukrainian men suffering from obesity. We examined 396 men aged 40-89 years. Depending on their BMI all the subjects were divided into two groups: Group I - patients with obesity whose BMI was $\geq 30 \mathrm{~kg} / \mathrm{m}^{2}(\mathrm{n}=129)$ and Group II - patients without obesity and BMI of $<30 \mathrm{~kg} / \mathrm{m}^{2}(\mathrm{n}=267)$. The BMD of total body, lumbar spine $\mathrm{L}_{1}-\mathrm{L}_{4}$, femoral neck and forearm were measured by DXA (Prodigy, GEHC Lunar, Madison, WI, USA). The TBS of $\mathrm{L}_{1}-\mathrm{L}_{4}$ was assessed by means of TBS iNsight ${ }^{\circledR}$ software installed on DXA machine (product of Med-Imaps, Pessac, France). In general, obese men had a significantly higher BMD of lumbar spine $\mathrm{L}_{1}-\mathrm{L}_{4}$, femoral neck, total body and ultradistal forearm $(p<0.001)$ in comparison with men without obesity. The TBS of $\mathrm{L}_{1}-\mathrm{L}_{4}$ was significantly lower in obese men compared to non-obese ones $(\mathrm{p}<$ 0.001). BMD of lumbar spine $\mathrm{L}_{1}-\mathrm{L}_{4}$, femoral neck and total body significantly differ in men aged 40-49, 50-59, 60-69, and 80-89 years $(\mathrm{p}<0.05)$. At the same time, in men aged 70-79 years, BMD of lumbar spine $\mathrm{L}_{1}-\mathrm{L}_{4}(\mathrm{p}=0.46)$, femoral neck $(\mathrm{p}=0.18)$, total body $(p=0.21)$, ultra-distal forearm $(p=0.13)$, and TBS $(p=0.07)$ did not significantly differ. A significant positive correlation between the fat mass and the BMD at different sites was observed. However, the correlation between the fat mass and TBS of $\mathrm{L}_{1}-\mathrm{L}_{4}$ was also significant, though negative.
\end{abstract}

Keywords - Bone mineral density, trabecular bone score, obesity, men.

\section{INTRODUCTION}

$T$ HERE is a growing recognition of the fact that osteoporosis and fractures in older men are significant public health problems contributing towards disability and premature death. Osteoporosis is defined as a systemic bone disease characterized by a low bone mass and mircoarchitectural deterioration of bone tissue, with a subsequent increase of bone fragility and susceptibility to fracture. BMD, as measured by dual X-ray absorptiometry (DXA), has been the gold standard tool both for osteoporosis detection and monitoring of treatment efficacy. Unfortunately, BMD alone cannot explain the inconsistency between fat and bone metabolism [8]. The mechanism in which obesity may increase the risk of fractures is unknown but probable

V. Povoroznyuk, A. Musiienko, and N. Dzerovych are with D. F. Chebotarev Institute of gerontology NAMS Ukraine, Kyiv, Ukraine (e-mail: okfpodac@ukr.net,musienko_anya@ukr.net, zeronat@ukr.net).

R. Povoroznyuk is with Institute of Philology, Kyiv National Taras Shevchenko University, Kyiv, Ukraine (e-mail: rocksol24@yandex.ru). influence can be divided into BMD-dependent and/or BMDindependent mechanisms [7]. The TBS is a new grey-level texture parameter that can be computed from DXA images, which makes up for the defects of the BMD. According to the results of numerous laboratory and clinical studies, low body weight or low BMI is a strong predictor of low BMD and increased fracture risk in both males and females. However, higher fracture risk in an underweight relative to normal weight may not translate into a similarly strong protective effect of elevated BMI [10], [13]. In some studies, overweight or obesity has been linked to an increased fracture risk, a finding of public health importance given the epidemic obesity. The relationship between fractures and weight, height, and BMI is complex and appears to vary by age and fracture site. Studies in women and men showed that overweight/obese individuals are at increased fracture risk after adjustment for the expected higher BMD but not when the effect of BMD is excluded from the prediction model [3].

Obesity is one of the most common chronic diseases in the world and has become noninfectious epidemic. According to the World Health Organization (WHO) in 2014 obesity was reported in $13 \%$ of the adult population of the world $(11 \%$ of men and $15 \%$ women). According to the Ministry of Health of Ukraine from obesity suffers about $20.1 \%$ of our population (male obesity occurs in $15.9 \%$ and $25.7 \%$ in - women) [5].

Obesity is penalized the healthy bone metabolism through specific mechanisms and using various mediators. On the process of bone remodeling can affect mediators from the immune system, fat tissue, intestines and even the brain. Obesity may increase adipocyte differentiation and fat accumulation while decreasing osteoblast differentiation and bone formation. Since adipocytes and osteoblasts are derived from a common multipotential mesenchymal stem cell. Important mediators influence is adipokines such as adiponectin and leptin. Excessive secretion of leptin at obesity directly may contribute to the differentiation of osteoblasts and influence the process of bone resorption or indirectly through up-regulated proinflammatory cytokine production. Proved that adiponectin has a stimulating effect on bone, but at the same time it can stimulate RANKL and inhibit osteoblast production osteoproteherina [1], [4], [9], [12].

The increased circulating and tissue proinflammatory cytokines (TNF-a, IL-1, and IL-6) is likely to promote osteoclast activity and bone resorption through modification of the receptor activator of NF-B (RANK)/RANK ligand/osteoprotegerin pathway. The high fat intake may interfere with the intestinal calcium absorption and therefore decrease calcium availability for the bone formation [1], [2]. 
The results of a meta-analysis of 60000 men and women from 12 prospective, population based cohorts show that total fractures, osteoporotic fractures, and hip fractures are all inversely correlated to the BMI in both men and women [6]. Several recent studies demonstrate that the obesity protects human body against fractures and at the same time that the obesity is a risk factor for certain types of fracture. Namely, the study by Hsu et al., carried out in a large cohort of Chinese men and women, shows that the frequency of nonspine fractures is significantly higher in subjects with a higher percentage of body fat, independent of their body weight [16].

The Spanish retrospective cohort study was carried out on 186171 men $\geq 65$ years old, of whom 139419 (74.9\%) had an available BMI measurement. Only $0.6 \%(n=806)$ of these men were underweight $\left(\mathrm{BMI}<18.5 \mathrm{~kg} / \mathrm{m}^{2}\right)$; therefore, they were categorized as underweight/ normal $\left(\mathrm{BMI}<25 \mathrm{~kg} / \mathrm{m}^{2}\right.$, $\mathrm{n}=26.298)$, overweight $\left(25<\mathrm{BMI}<30 \mathrm{~kg} / \mathrm{m}^{2}, \mathrm{n}=70.851\right)$, or obese $\left(B M I \geq 30 \mathrm{~kg} / \mathrm{m}^{2}, \mathrm{n}=42.270\right)$. A statistically significant reduction in clinical spine and hip fractures was observed in obese (RR, 0.65; 95\% CI, 0.53-0.80 and RR, 0.63; 95\% CI, $0.54-0.74$, respectively), and overweight men (RR, $0.77 ; 95 \%$ CI, 0.64-0.92 and RR, 0.63; 95\% CI, 0.55-0.72, respectively) when compared to underweight/normal men. Additionally, obese men had fewer wrist/forearm (RR, 0.77; 95\% CI, 0.610.97 ) and pelvic (RR, $0.44 ; 95 \% \mathrm{CI}, 0.28-0.70)$ fractures than underweight/normal men. Conversely, multiple rib fractures were more frequent in overweight (RR, 3.42; 95\% CI, 1.03 11.37) and obese men (RR, 3.96; 95\% CI, 1.16-13.52) [15].

In the meta-analysis reported by De Laet et al. [13], no additional increase in the risk of hip fracture was seen in men with higher than normal BMI. However, in the osteoporotic fractures in men study, a population based study of men aged $\geq 65$ years, obesity was associated with a higher incidence of non-spine and non-hip fractures when compared with normal weight men after adjustment for hip BMD. In this study, the majority of men (72\%) were overweight or obese, and fewer than $1 \%$ were underweight. The results are therefore consistent with studies that have shown the highest risk of hip fracture in underweight individuals, but suggest that obesity may increase the risk of non-spine and non-hip fractures independently of BMD. In the present study, BMD measurements were not available, and thus, it was not possible to investigate whether the observed relationship between BMI and fractures was modified by adjustment for BMD [14]. Thus, conflicting data suggest that there is a complex relationship between fat mass and bone mass, likely to depend on the patient's age, sex, and ethnicity [11]. High risk of nonvertebral fractures in people with obesity can be caused by changes in bone microarchitecture and reduced bone quality. The aim of our study was to evaluate the relationship between the BMD and TBS parameters in Ukrainian obese men.

\section{MATERIALS AND METHODS}

We have examined 396 men aged 40-89 years (mean age $60.6 \pm 11.9$ years; mean height $-174.4 \pm 6.7 \mathrm{~cm}$; mean weight $84.5 \pm 14.6 \mathrm{~kg}$, mean BMI $-27.8 \pm 4.4 \mathrm{~kg} / \mathrm{m}^{2}$ ). The men were divided into the following groups depending on BMI: I - 129 men with obesity, $B M I \geq 30 \mathrm{~kg} / \mathrm{m}^{2}$ (mean age $-59.9 \pm 10.4$ years; mean height $-174.4 \pm 6.8 \mathrm{~cm}$; mean weight $-100.0 \pm 9.8$ $\mathrm{kg}$, mean BMI - 32.9 $\pm 2.6 \mathrm{~kg} / \mathrm{m}^{2}$ ), II - 267 men without obesity, BMI $<30 \mathrm{~kg} / \mathrm{m}^{2}$ (mean age $-60.9 \pm 12.5$ years; mean height $-174.3 \pm 6.7 \mathrm{~cm}$; mean weight $-77.1 \pm 9.8 \mathrm{~kg}$, mean BMI $-25.3 \pm 2.6 \mathrm{~kg} / \mathrm{m}^{2}$ ). Our study included healthy men who do not suffer from metabolic disorders and were not taking drugs that may affect bone metabolism (steroids, estrogen and bisphosphonates).

BMD at total body, lumbar spine $\mathrm{L}_{1}-\mathrm{L}_{4}$, femoral neck, and forearm was measured by the DXA method (Prodigy, GEHC Lunar, Madison, WI, USA). TBS iNsight ${ }^{\circledR}$ software (MedImaps, Pessac, France) was installed on our DXA machine for the express purpose of assessing TBS at the $\mathrm{L}_{1}-\mathrm{L}_{4}$. BMI was calculated from height and weight $\left(\mathrm{kg} / \mathrm{m}^{2}\right)$.

The study results are presented in the following manner: $\mathrm{M} \pm \mathrm{SD}$. We performed a one-way ANOVA test, multiple regression and correlation analysis. Significance was set at $\mathrm{p}<0.05$. "Statistika 6.0" (C) StatSoft, Inc. was used for data processing purposes.

\section{RESULTS}

In the total group, we found that obese men have a significantly higher BMD of lumbar spine $\mathrm{L}_{1}-\mathrm{L}_{4}$ (I $1.289 \pm 0.212 \mathrm{~g} / \mathrm{cm}^{2}$, II $-1.172 \pm 0.237 \mathrm{~g} / \mathrm{cm}^{2} ; \quad \mathrm{F}=22.59$; $\mathrm{p}<0.001$ ), femoral neck (I $-0.964 \pm 0.148 \mathrm{~g} / \mathrm{cm}^{2}$, II $0.914 \pm 0.150 \mathrm{~g} / \mathrm{cm}^{2} ; \mathrm{F}=25.18 ; \mathrm{p}<0.001$ ), total body (I $1.277 \pm 0.098 \mathrm{~g} / \mathrm{cm}^{2}$, II $-1.185 \pm 0.118 \mathrm{~g} / \mathrm{cm}^{2} ; \mathrm{F}=57.38$; $\mathrm{p}<0.001)$ and ultra-distal forearm ( $\mathrm{I}-0.555 \pm 0.086 \mathrm{~g} / \mathrm{cm}^{2}$, II $\left.0.494 \pm 0.095 \mathrm{~g} / \mathrm{cm}^{2} ; \mathrm{F}=37.57 ; \mathrm{p}<0.001\right)$ in comparison with men without obesity. TBS $\left(\mathrm{L}_{1}-\mathrm{L}_{4}\right)$ was significantly lower in obese men compared to non-obese men (I - 1.053 \pm 0.161 , II $1.197 \pm 0.167 ; \mathrm{F}=66.48 ; \mathrm{p}<0.001)$.

TABLE I

BMD OF LUMBAR SPINE $\left(\mathrm{L}_{1}-\mathrm{L}_{4}\right)$ IN UKRAINIAN OBESE AND NON-OBESE MEN

\begin{tabular}{cccc}
\hline \hline $\begin{array}{c}\text { Age groups, } \\
\text { years }\end{array}$ & & $\begin{array}{c}\text { BMD lumbar spine } \\
\left(\mathrm{L}_{1}-\mathrm{L}_{4}\right), \mathrm{g} / \mathrm{cm}^{2}\end{array}$ & $\mathrm{p}$ \\
\hline \multirow{2}{*}{$40-49$} & without obesity $(\mathrm{n}=58)$ & $1.183 \pm 0.217$ & 0.278 \\
& with obesity $(\mathrm{n}=20)$ & $1.243 \pm 0.189$ & \\
\multirow{2}{*}{$50-59$} & without obesity $(\mathrm{n}=69)$ & $1.083 \pm 0.207$ & $<0.001$ \\
& with obesity $(\mathrm{n}=44)$ & $1.233 \pm 0.197$ & \\
\multirow{2}{*}{$60-69$} & without obesity $(\mathrm{n}=58)$ & $1.161 \pm 0.230$ & $<0.001$ \\
& with obesity $(\mathrm{n}=43)$ & $1.330 \pm 0.207$ & \\
$70-79$ & without obesity $(\mathrm{n}=64)$ & $1.277 \pm 0.265$ & 0.465 \\
& with obesity $(\mathrm{n}=15)$ & $1.331 \pm 0.236$ & \\
\multirow{2}{*}{$80-89$} & without obesity $(\mathrm{n}=18)$ & $1.142 \pm 0.198$ & 0.005 \\
& with obesity $(\mathrm{n}=7)$ & $1.143 \pm 0.255$ & \\
\hline \hline
\end{tabular}




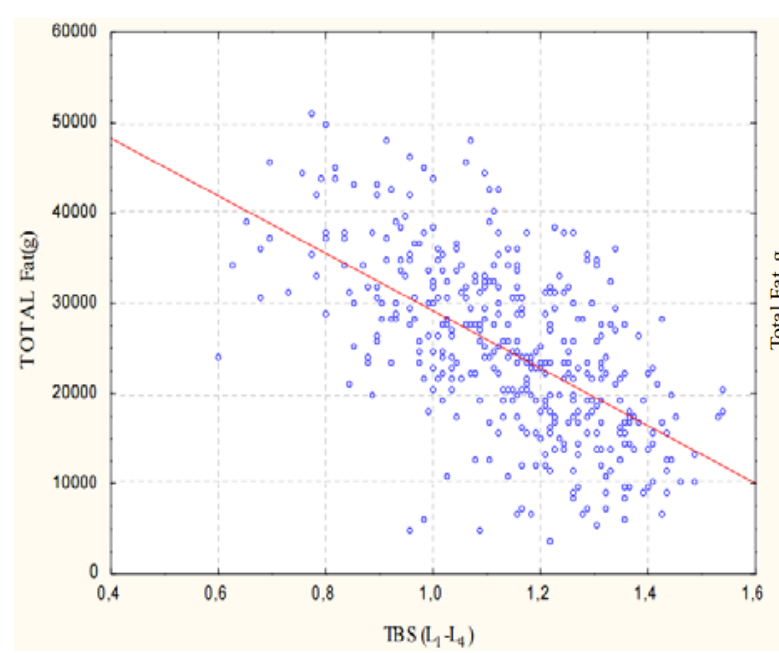

(a)

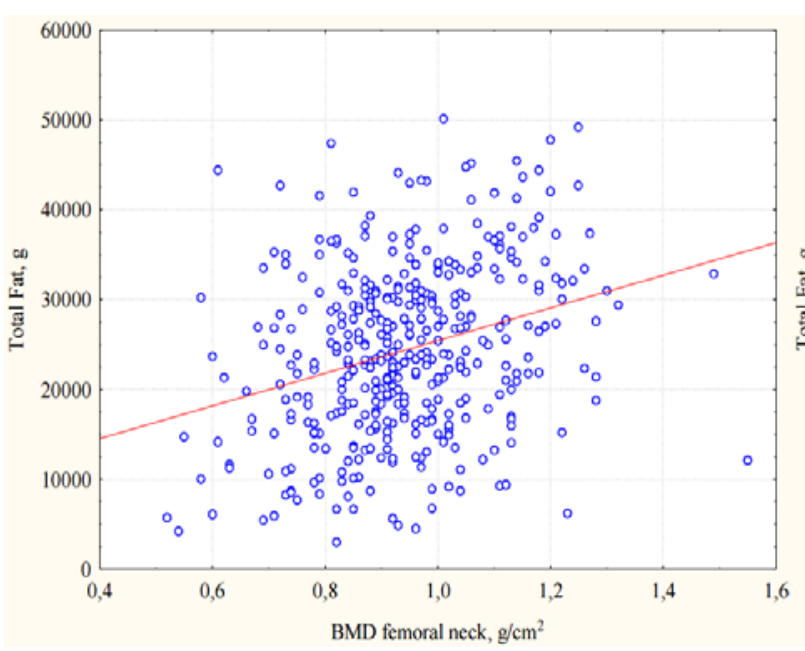

(c)

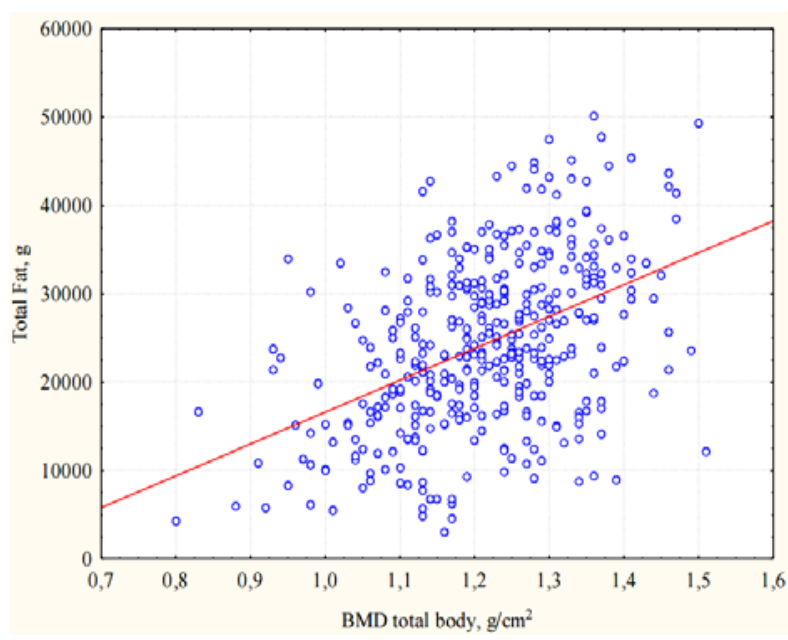

(e)

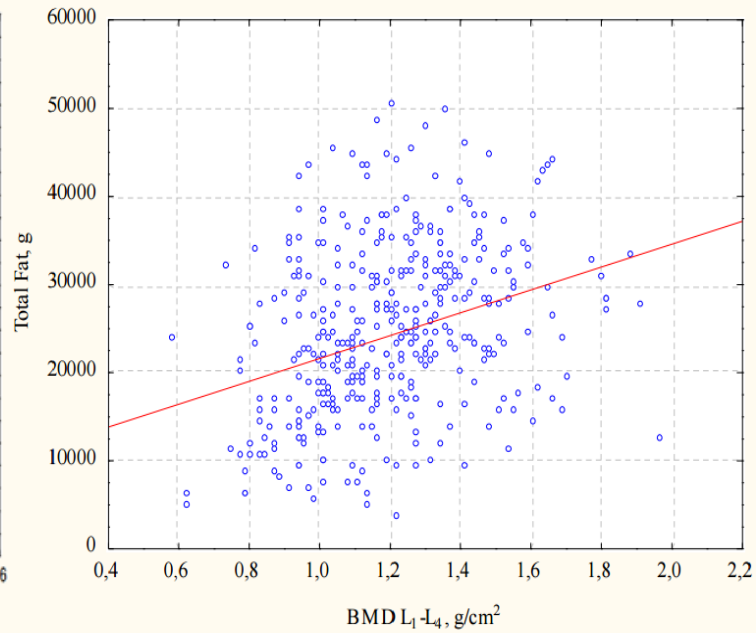

(b)

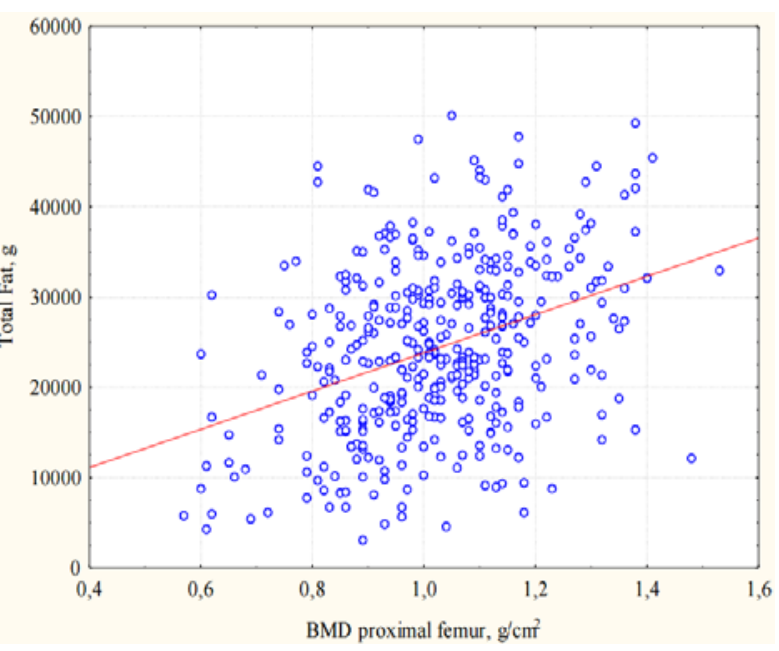

(d)

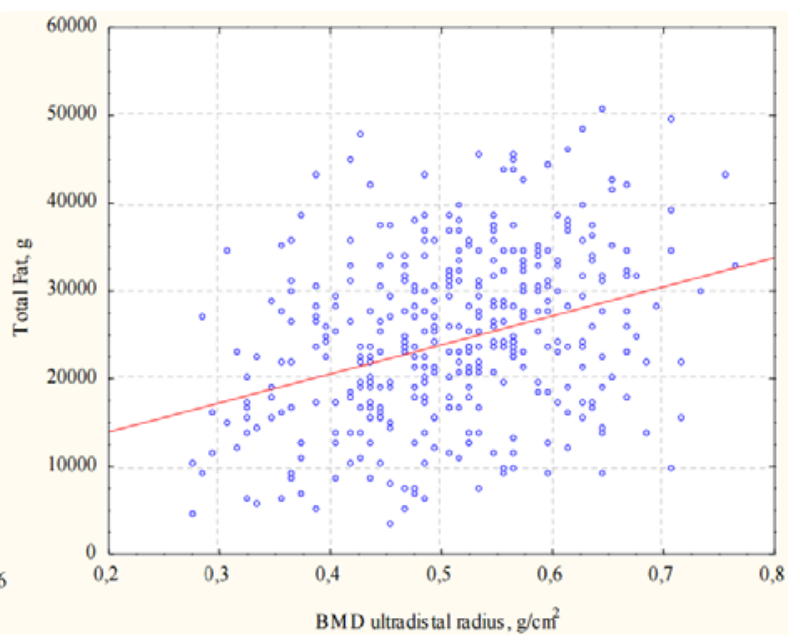

(f)

Fig. 1 Correlation between fat mass and TBS $\left(\mathrm{L}_{1}-\mathrm{L}_{4}\right)$, BMD lumbar spine $\left(\mathrm{L}_{1}-\mathrm{L}_{4}\right)$, femoral neck, proximal femur, total body and ultradistal radius. Note. Linear regression equations: (a) Total Fat, $g=51890.2-15071.4 * \mathrm{TBS}\left(\mathrm{L}_{1}-\mathrm{L}_{4}\right)(\mathrm{r}=-0.60 ; \mathrm{p}<0.001)$; (b) Total Fat, $\mathrm{g}=8667.3+$ 12.9*BMD lumbar spine $\left(\mathrm{L}_{1}-\mathrm{L}_{4}\right), \mathrm{g} / \mathrm{cm}^{2}(\mathrm{r}=0.32 ; \mathrm{p}<0.001)$; (c) Total Fat, $\mathrm{g}=7290.3+18161.0 * \mathrm{BMD}$ femoral neck, $\mathrm{g} / \mathrm{cm}^{2}(\mathrm{r}=0.29 ; \mathrm{p}<0.001)$; (d) Total Fat, $g=2615.5+21207.4 * B M D$ proximal femur, $g / \mathrm{cm}^{2}(\mathrm{r}=0.37 ; \mathrm{p}<0.001)$; (e) Total Fat, $\mathrm{g}=-19492.1+36092.9 * \mathrm{BMD}$ total body, $\mathrm{g} / \mathrm{cm}^{2}(\mathrm{r}=0.45 ; \mathrm{p}<0.001)$; (f) Total Fat, $\mathrm{g}=7371.5+33035.5^{*} \mathrm{BMD}$ ultradistal radius, $\mathrm{g} / \mathrm{cm}^{2}(\mathrm{r}=0.34 ; \mathrm{p}<0.001)$ 
TABLE II

BMD OF FEMORAL NECK In UKRAINIAN OBESE AND NON-OBESE MEN

\begin{tabular}{cccc}
\hline \hline $\begin{array}{c}\text { Age groups, } \\
\text { years }\end{array}$ & & $\begin{array}{c}\text { BMD femoral neck, } \\
\mathrm{g} / \mathrm{cm}^{2}\end{array}$ & $\mathrm{p}$ \\
\hline \multirow{2}{*}{$40-49$} & without obesity $(\mathrm{n}=58)$ & $0.991 \pm 0.144$ & 0.506 \\
& with obesity $(\mathrm{n}=20)$ & $1.047 \pm 0.141$ & \\
\multirow{2}{*}{$50-59$} & without obesity $(\mathrm{n}=69)$ & $0.898 \pm 0.144$ & 0.001 \\
& with obesity $(\mathrm{n}=44)$ & $0.994 \pm 0.152$ & \\
$60-69$ & without obesity $(\mathrm{n}=58)$ & $0.907 \pm 0.149$ & 0.003 \\
& with obesity $(\mathrm{n}=43)$ & $0.993 \pm 0.121$ & \\
$70-79$ & without obesity $(\mathrm{n}=64)$ & $0.899 \pm 0.148$ & 0.184 \\
& with obesity $(\mathrm{n}=15)$ & $0.955 \pm 0.129$ & \\
$80-89$ & without obesity $(\mathrm{n}=18)$ & $0.800 \pm 0.103$ & 0.075 \\
& with obesity $(\mathrm{n}=7)$ & $0.942 \pm 0.290$ & \\
\hline \hline
\end{tabular}

TABLE III

BMD of Total Body in UKRaINIAN OBESE AND Non-Obese Men

\begin{tabular}{cccc}
\hline \hline $\begin{array}{c}\text { Age groups, } \\
\text { years }\end{array}$ & & BMD total body, $\mathrm{g} / \mathrm{cm}^{2}$ & $\mathrm{p}$ \\
\hline \multirow{2}{*}{$40-49$} & without obesity $(\mathrm{n}=58)$ & $1.123 \pm 0.522$ & 0.002 \\
& with obesity $(\mathrm{n}=20)$ & $1.309 \pm 0.103$ & \\
\multirow{2}{*}{$50-59$} & without obesity $(\mathrm{n}=69)$ & $1.162 \pm 0.119$ & $<0.001$ \\
& with obesity $(\mathrm{n}=44)$ & $1.267 \pm 0.099$ & \\
\multirow{2}{*}{$60-69$} & without obesity $(\mathrm{n}=58)$ & $1.183 \pm 0.117$ & $<0.001$ \\
& with obesity $(\mathrm{n}=43)$ & $1.281 \pm 0.089$ & \\
$70-79$ & without obesity $(\mathrm{n}=64)$ & $1.205 \pm 0.119$ & 0.209 \\
& with obesity $(\mathrm{n}=15)$ & $1.248 \pm 0.118$ & \\
\multirow{2}{*}{$80-89$} & without obesity $(\mathrm{n}=18)$ & $1.092 \pm 0.091$ & $<0.001$ \\
& with obesity $(\mathrm{n}=7)$ & $1.281 \pm 0.085$ & \\
\hline \hline
\end{tabular}

TABLE IV

BMD OF ULTRADISTAL RADIUS IN UKRAINIAN OBESE AND NON-OBESE MEN

\begin{tabular}{cccc}
\hline \hline $\begin{array}{c}\text { Age groups, } \\
\text { years }\end{array}$ & & $\begin{array}{c}\text { BMD ultradistal } \\
\text { radius, } \mathrm{g} / \mathrm{cm}^{2}\end{array}$ & $\mathrm{p}$ \\
\hline \multirow{2}{*}{$40-49$} & without obesity $(\mathrm{n}=58)$ & $0.522 \pm 0.086$ & 0.003 \\
& with obesity $(\mathrm{n}=20)$ & $0.589 \pm 0.078$ & \\
$50-59$ & without obesity $(\mathrm{n}=69)$ & $0.505 \pm 0.095$ & 0.009 \\
& with obesity $(\mathrm{n}=44)$ & $0.553 \pm 0.088$ & \\
\multirow{2}{*}{$60-69$} & without obesity $(\mathrm{n}=58)$ & $0.491 \pm 0.094$ & $<0.001$ \\
& with obesity $(\mathrm{n}=43)$ & $0.555 \pm 0.068$ & \\
$70-79$ & without obesity $(\mathrm{n}=64)$ & $0.489 \pm 0.092$ & 0.128 \\
& with obesity $(\mathrm{n}=15)$ & $0.533 \pm 0.124$ & \\
$80-89$ & without obesity $(\mathrm{n}=18)$ & $0.394 \pm 0.076$ & 0.002 \\
& with obesity $(\mathrm{n}=7)$ & $0.518 \pm 0.091$ & \\
\hline \hline
\end{tabular}

TABLE V

TBS $\left(\mathrm{L}_{1}-\mathrm{L}_{4}\right)$ IN UKRAINIAN OBESE AND NON-OBESE MEN

\begin{tabular}{cccc}
\hline \hline Age groups, years & & TBS L $_{1}-\mathrm{L}_{4}$ & $\mathrm{p}$ \\
\hline \multirow{2}{*}{$40-49$} & without obesity $(\mathrm{n}=58)$ & $1.265 \pm 0.136$ & $<0.001$ \\
& with obesity $(\mathrm{n}=20)$ & $1.082 \pm 0.118$ & \\
\multirow{2}{*}{$50-59$} & without obesity $(\mathrm{n}=69)$ & $1.198 \pm 0.184$ & $<0.001$ \\
& with obesity $(\mathrm{n}=44)$ & $1.028 \pm 0.179$ & \\
\multirow{2}{*}{$60-69$} & without obesity $(\mathrm{n}=58)$ & $1.206 \pm 0.136$ & $<0.001$ \\
& with obesity $(\mathrm{n}=43)$ & $1.077 \pm 0.133$ & \\
$70-79$ & without obesity $(\mathrm{n}=64)$ & $1.143 \pm 0.176$ & 0.071 \\
& with obesity $(\mathrm{n}=15)$ & $1.050 \pm 0.182$ & \\
\multirow{2}{*}{$80-89$} & without obesity $(\mathrm{n}=18)$ & $1.144 \pm 0.188$ & 0.038 \\
& with obesity $(\mathrm{n}=7)$ & $0.907 \pm 0.143$ & \\
\hline \hline
\end{tabular}

When we analyzed BMD depending on age, we determined that $\mathrm{BMD}$ of lumbar spine $\mathrm{L}_{1}-\mathrm{L}_{4}$, femoral neck, total body and ultra-distal forearm significantly differed in men aged 40-49, $50-59,60-69$, and $80-89$ years $(\mathrm{p}<0.05)$. At the same time, we did not find any significant differences in BMD of lumbar spine $\mathrm{L}_{1}-\mathrm{L}_{4} \quad(\mathrm{p}=0.46)$, femoral neck $(\mathrm{p}=0.18)$, total body $(\mathrm{p}=0.21)$, and ultra-distal forearm $(\mathrm{p}=0.13)$ with men aged 70 79 years (Tables I-IV). By contrast, TBS of $\mathrm{L}_{1}-\mathrm{L}_{4}$ significantly decreased in obese men as compared to men without obesity (Table V).

Fat mass and BMD status showed a significant positive inter-relation at various sites. Correlation between fat mass and TBS $\left(\mathrm{L}_{1}-\mathrm{L}_{4}\right)$ was significant and negative (Fig. 1).

\section{CONCLUSION}

In Ukrainian men, obesity negatively affected $T B S \mathrm{~L}_{1}-\mathrm{L}_{4}$, despite a significantly higher BMD at all measured sites (compared with men of no obesity). TBS $\left(\mathrm{L}_{1}-\mathrm{L}_{4}\right)$ significantly differed in the examined men depending on age. The study results reveal a significant positive correlation between fat mass and BMD. Correlation between fat mass and TBS $\left(\mathrm{L}_{1^{-}}\right.$ $\mathrm{L}_{4}$ ) was significant and negative.

\section{REFERENCES}

[1] M. J. Gonçalves, A. M. Rodrigues, H. Canhão, J. E. Fonseca "Osteoporosis: from bone biology to individual treatment decision," Acta Med. Port., vol. 26, no. 4, pp. 445-55, 2013.

[2] J. J. Cao "Effects of obesity on bone metabolism," J. Orthop. Surg. Res., vol. 15 , no. 6 , p. 30,2011

[3] W. D. Leslie, E. S. Orwoll, C. M. Nielson, S. N. Morin, S. R. Majumdar, H. Johansson, A. Odén, E. V McCloskey, J. A. Kanis "Estimated Lean Mass and Fat Mass Differentially Affect Femoral Bone Density and Strength Index but Are Not FRAX Independent Risk Factors for Fracture,” J Bone Miner Res., vol. 29, no. 11, pp 2511-2519, 2014.

[4] A. Faje, A. Klibanski "Body composition and skeletal health: too heavy? Too thin?," Curr. Osteoporos. Rep., vol. 10, no. 3, pp. 208-16, 2012.

[5] Nutrition, Physical Activity and Obesity // Available online: http://www.euro.who.int/ru/health-topics/diseaseprevention/nutrition/country-work/ukraine2 Accessed on 12 Jan 2017.

[6] S. Gonnelli, C. Caffarelli, R. Nuti "Obesity and fracture risk," Clin. Cases Miner. Bone Metab., vol. 11, no. 1, pp. 9-14, 2014

[7] B. A. Gower, K. Casazza "Divergent effects of obesity on bone health," J. Clin. Densitom., vol. 16, no. 4, pp. 450-4, 2013.

[8] S. Lv, A. Zhang, W. Di, Y. Sheng, P. Cheng, H. Qi, J. Liu, J. Yu, G. Ding, J. Cai \& B. Lai. "Assessment of Fat distribution and Bone quality with Trabecular Bone Score (TBS) in Healthy Chinese Men," Scientific Reports, vol. 26, pp 1-8, 2016.

[9] D. Naot, J. Cornish "Cytokines and Hormones That Contribute to the Positive Association between Fat and Bone," Front Endocrinol (Lausanne), vol. 9, no. 5, p. 70, 2014.

[10] C. M. Nielson, P. Srikanth, E. S. Orwoll "Obesity and fracture in men and women: an epidemiologic perspective," J. Bone Miner. Res., vol. 27, no. 1, pp. 1-10, 2012.

[11] C. J. Rosen, M. L. Bouxsein "Mechanisms of disease: is osteoporosis the obesity of bone?," Nature clinical practice, vol. 2 no. 1, pp. 35-43, 2006.

[12] S. Sharma, T. V. Randon, S. Mahajan et al. "Obesity: Friend or foe for osteoporosis,” J. Midlife Health, vol. 5, no. 1, pp. 6-9, 2014.

[13] C. De Laet, J. A. Kanis, A. Oden, et al. "Body mass index as a predictor of fracture risk: a meta-analysis," Osteoporos Int., vol. 16, pp. 13301338, 2005.

[14] C. M. Nielson, L. M. Marshall, A. L. Adams, E. S. LeBlanc, P. M. Cawthon, K. Ensrud, M. L. Stefanick, E. Barrett-Connor, E. S. Orwoll "Osteoporotic Fractures in Men Study Research Group. BMI and fracture risk in older men: the osteoporotic fractures in men study (MrOS) ,"J Bone Miner Res., vol. 26, no. 3, pp 496-502, 2011.

[15] M. O. Premaor, J. E. Compston, F. F.Avilés, A. Pagès-Castellà, X. Nogués, A. Díez-Pérez, D. Prieto-Alhambra "The Association Between Fracture Site and Obesity in Men: A Population-Based Cohort Study," J Bone Miner Res., vol. 28, no. 8, pp 1771-1777. 2013. 
World Academy of Science, Engineering and Technology

International Journal of Medical and Health Sciences

Vol:11, No:5, 2017

[16] Y. H. Hsu, S. A. Venners, Henry A Terwedow, Y. Feng, T. Niu, Z. Li, N. Laird, J. D. Brain, S. R. Cummings, M. L. Bouxsein, C. J. Rosen, X. $\mathrm{Xu}$ "Relation of body composition, fat mass, and serum lipids to osteoporotic fractures and bone mineral density in Chinese men and women," Am J Clin Nutr., vol. 83, pp. 146 -54, 2006. 